\title{
Osmanlı Devleti Okmeydanlarında Menzil Okçuluğu Eğitimi
}

\author{
Serkan Necati METIN ${ }^{1 *}$ \\ Ahmet UYSAL ${ }^{2}$ iD \\ ${ }^{1}$ Sakarya Uygulamali Bilimler Üniversitesi, SAKARYA \\ ${ }^{2}$ Balıkesir Üniversitesi Türkçe ve Sosyal Bilimler Eğitimi Bölümü, BALIKESIR
}

DOI: $10.31680 /$ gaunjss.770006

Orijinal Makale / Original Article

Geliş Tarihi / Received: 15.07.2020
Kabul Tarihi / Accepted: 07.09.2020

\section{Öz}

Menzil okçuluğu ilk olarak nerede ve ne zaman yapıldığı kesin olarak bilinmemekle birlikte Türk tarihi için çok önemli bir yere sahip olan Dede Korkut hikayelerinde uzağa ok atmak olarak rastlanılmaktadır (Yücel, 2015:67). Menzil Okçuluğu, Osmanlı Devleti'nin en önemli sporlarından biri olduğu söylenebilir. Çünkü sadece menzil okçuluğu için hemen hemen bütün önemli şehirlerinde ok meydanı kurulmuştur. İlk ok meydanının nerede kurulduğuna dair ise çeşitli fikirler mevcuttur. Kunter, ilk ok meydanının Bursa da yapıldığını belirtirken (Kunter, 1942), Yücel, Edirne olarak bildirmiştir. Asıl olan ise 38 farklı meydan ve 100 den fazla menzil olduğudur (Yücel, 2015:69; Acar ve Özveri, 2017). Evliya Çelebi de Seyahatname adlı eserinde birçok şehirde ok meydanının varlığından söz etmiştir (Akın Zorba, 2014). Osmanlı Devleti'nde menzil okçusu olabilmek yani kemankeş sayılabilmek için ahlaki ve fiziki yeterliliğe sahip olmak gerekirdi. Kemankeş eğitimi oldukça zorluydu. Meydanlarda atış yapmadan önce bir atıcının, bir üstattan ilk olarak Küçük kabza ve Büyük Kabza alması gerekirdi(Güven, 1999). Atıcıların (kemankeş) yalnız iyi birer atıcı olması yetmezdi. Aralarında her türlü rekabetin üstünde, saygı ve sevgiye dayanan bir dostluk ve kardeşlik havasının esmesine de dikkat edilirdi. İhtiyarlara, kıdemli atıcılara ve üstada saygı göstermek şarttı. Risalelerde, ünlü okçuların biyografileri verilirken sadece atıcılık gücü değil, aynı zamanda ne kadar sağlam bir kişilik ve karakter sahibi oldukları da belirtilirdi (Göksu, 2018). Bu çalışmada menzil okçusu olabilmek için gerekli olan eğitimin sistematik ve bilimsel olarak nasıl verildiği üzerinde durularak menzil okçuluğu bağlamında bir eğitimi kurumu olarak okçuluğun şahsiyet ve değerler eğitimi boyutu da eldeki kaynaklar ışığında açıklanmaya çalışılmıştır.

Anahtar Kelimeler: Osmanlı Devleti, menzil okçuluğu, okmeydanlari, değerler eğitimi, spor

\section{Range Archery Education in Ottoman State' Arrow Squares}

\begin{abstract}
While the range archery is not known exactly where and when it was first performed, Dede Korkut stories, which have a very important place in Turkish history, are encountered as throwing arrows in the stories. Range Archery can be said to be one of the most important sports of the Ottoman State. Because only for range archery, arrow square was established in almost all important cities. There are various ideas about where the first arrow square was founded. Kunter stated that the first arrow square was built in Bursa, while Yücel reported it as Edirne. The main thing is that there are 38 different squares and more than 100 ranges (Yücel, 2015: 69; Acar \& Özveri, 2017). Evliya Çelebi also mentioned the existence of an arrow square in many cities in his book Seyahatname (Akın Zorba, 2014). In order to be a range archery in the Ottoman State, that is to say, kemankeş, it was necessary to have morality and physical competence. Kemankeş education was very difficult. Before shooting in the squares, a shooter had to take a small and big hilt from a master (Güven, 1999).It was not enough that the shooters (kemankeş) were only good shooters. It was also paid attention to the atmosphere of friendship and brotherhood based on respect and love above all kinds of competition. Respect for the elders, senior shooters and master was essential. In the treatises, while bibliographies of famous archers were given, it was stated that it was not only the power of shooting but also how strong personality and character they had (Göksu, 2018). In this study, it was tried to explain the personality and values education dimension of archery as a training institution in the context of range archery, by focusing on how the training required to become a range archery is given systematically and scientifically.
\end{abstract}

Keywords: Ottoman state, range archery, arrow squares, values education, sports

\footnotetext{
* Sorumlu Yazar: Serkan Necati METİN
}

E-mail: serkanmetin1985@windowslive.com 


\section{Giriş}

Türk okçuluğu temeli M.Ö. 1000'li yıllara dayanan bir ekoldür. İskitler ile başlayan gelişim Hun'lar ve diğer Orta Asya Türk toplumları ile devam etmiş, nihayetinde Selçuklu ve Osmanlılar ile günümüze değin taşınmıştır (Archer \& Ferris, 2002).

Türk milletinin ise ata binmeye ve yay kullanmaya doğuştan yetenekli olduğu söylenebilir. Tarih boyunca at üzerinde kullandıkları yay ile birçok savaşta galip gelen Türkler, kendi çocuklarının oyunlarında dahi okçuluk ile uğraşmışlardı. Bu oyunlar ile büyüyen çocuklar delikanlı olduklarında iyi ok atar duruma gelirdi. Bunlardan bazıları ise kabza alarak ok meydanlarında menzil atıp taş diker (Kahraman, 1995:387) ve böylelikle ismini ölümsüzleştirmeye çalışırdı (Dever \& İslam, 2015; Bir, Kaçar, \& Acar, 2006).

Menzil okçusu olmak isteyen kişi ilk olarak bir okmeydanına gidip bu isteğini belirtirdi. Ahlaki olarak gerekli şartları taşımakta okmeydanında eğitim almanın en önemli şartlarındandı. Çünkü birçok risalede kemankeşlerin sadece atıcılık yetenekleri değil aynı zamanda kişiliklerine de yer verilirdi. Bu bağlamda kemankeşler "salih, ehl-i sünnet, ehl-i iman, ruhu pak" gibi sıfatlarda kullanılmaktadır (Küçük, 2018). Okmeydanlarında eğitim almaya başlamadan önce ise bir kişinin ilk olarak kabza alması gerekirdi. Kabza almayan kimse okmeydanına giremez, okmeydanında atış yapamaz ve asla eğitim alamazdı. Kişinin ilk önce küçük kabza alarak kendisine bir üstat edinmesi daha sonra büyük kabza alarak menzil atışı yapabilecek seviyeye gelmesi, son olarak ise hayatının geri kalanında menzil okçusu olarak kalmasını sağlayacak şekilde idman yapması gerekirdi (Güven, 2003). Kısacası menzil okçusu olmak oldukça zor, menzil okçusu olarak kalmak ise güçlü bir sabır ve istek gerektirmekteydi.

Genel olarak bu süreç değerlendirildiğinde menzil okçuluğu eğitiminin kemankeşin hayatı boyunca devam edeceği ancak okmeydanında eğitimin ise kişinin küçük kabza almasıyla başladığı söylenebilir.

\section{Küçük Kabza Almak}

Kemankeş olmak isteyen kişi ilk olarak küçük kabza almak zorundaydı. Bunun için ise ilk olarak bir okçular tekkesine gidip bu arzusunu tekke intiyarlarına bildirir ve kendisine bir üstat verilmesini talep ederdi. Okmeydanı ihtiyarları ise kabza almaya talip olan bu kişinin ahlaki olarak atıcılığa uygun olup olmadığını, herhangi bir kötü 
Metin, S.N. ve Uysal, A. (2020). Osmanlı Devleti Okmeydanlarında Menzil Okçuluğu Eğitimi. Gaziantep Üniversitesi Spor Bilimleri Dergisi, 5(3), 276-285.

şöhretinin olup olmadığını araştırırdı. Eğer talip olan kişi hakkında olumsuz bir bulgu bulunamazsa kendisine daha önceden okmeydanında menzil atmış ve okçular sicil defterinde adı bulunan bir kemankeş üstat olarak verilirdi (Güven, 2003). Böylelikle kişi bir üstada şakird olmuş olurdu.

Kendisine üstat bulan şakird, üstadın önünde diz çöker, üstat sol eliyle yayı tutarken şakirde "Bismillah ve ali berekatü Resullu'llah. Kabza Cebrail Aleyhi's selam hu suphane ve Talialininemr-i şerifleriyle cennetten çıkıp ibtida oku Peygamber Aleyhi's selama getirdi. Sonra Hazret-i Sultan Enbiya-ı Salla'llahu ve Sellem'in izni şerifiyle Sa'd bin ebu Vakkas raziyallahüanh pirimiz olup kabzayı eshab-ı güzine verildi. Ondan birbirlerine emanet edilerek üstadım bana verdi. Bende emaneti sana teslim eyledim. Fi sebilillah niyet edip ok at gaza ile ve talip olan kabza aşığına bu minval üzere hayır ve dua ile teslim eyle" diyerek yapılan dua ile şakirdin sol eline olacak şekilde yayı verirdi. Sağ elinde o anda bulunan ok veya gezi de şakirdin sağ eline teslim ederdi. Bu seremoni neticesinde şakird küçük kabza alır ve bu durumdan sonra okmeydanında kabza talibi olarak bilinmeye başlardı (Vural \& Aksoy, 2010).

Küçük kabza alan şakird üstadından artık eğitim almaya başlardı. Üstadından kabza tutmasını, atıcılığın tekniğini, antrenmanlarını nasıl gerçekleştireceğini ve ahlaki olarak da bir kemankeşin nasıl olması gerektiğini öğrenirdi. Bunların dışında okmeydanlarında uyulması gereken örfi kuralları da öğrenen şakird büyük kabza alıncaya kadar üstadı ile çalışır ve üstadından eğitim alırdı.

\section{Büyük Kabza Almak}

Büyük kabza almak için $900 \mathrm{gez}$ mesafeye atış yapılması gerekmektedir (Ayanoğlu, 1974:12; Atalay \& Akbulut, 2013). Üstadı tarafından eğitimlerine devam eden şakird $900 \mathrm{gez}$ pişrev oku, $800 \mathrm{gez}$ azmayiş oku ile atabilecek duruma gelince ve üstadı da bu kanaatte olursa ok meydanı intiyarlarına giderek atış yapmak istediğini beyan ederdi (Aktepe, 2012:13). İhtiyarlar, şarkirdin bu talebi karşısında şakirdin hangi menzilde, hangi havada atacağını aynı zamanda yay ağırlı̆ını ve ok cinsini ve son olarak da yaycısı ve okçusunun kim olduğunu görüştükten sonra bir engel olmadığına dair kanaat getirirlerse izin verirlerdi (Kahraman, 1995:388).

Şakird meydan intiyarlarından izin aldıktan sonra gerekli olan şahitleri ayarlardı. Şahitler hususunda bazı kaynaklar iki ayak yeri iki hava yeri olmak üzere dört şahit istediğini beyan ederken (Kahraman, 1995:389), bazı kaynaklar ise hava yeri şahidin üç olduğu ve toplam beş şahidin bulunduğunu belirtmişlerdir (Güven, 
2003). Şahitlerin 1962 yılından sonra okçular sicil defterine kayıtlı kemankeşler olması istenirdi. O tarihten öncesi ise yaycı ve okçu esnaflardan da şahit olunabilirdi. Bunun sebebi ise o tarihte yürürlüğe giren Kanunname-i Rumat'dır (Kahraman, 1995:389).

Şakird atışın yapılabileceği müsait bir havada ustasını, yaycısını, okçusunu ve şahitlerini yanına alarak meydana gelirdi. Şakird isminin okçular siciline yazdırabileceği bu atışı "Ya Hak" diyerek yapardı. Şakirdin yaptığı bu atış eğer 900 gezi aştıysa orada bulunan havacı yeri şahitleri sarıklarını havaya atarak müjdeyi verirler ve buna destar bozmak denirdi (Kahraman, 1995:389).

Destar bozan şakird adını okçular sicil defterine yazdırır ve artık kemankeş ünvanına sahip olurdu. Yeni kemankeş olan atıcı okçular tekkesinde masraflarını kendisinin karşılayacağı bir ziyafet verir ve bu ziyafet akabinde ise Büyük Kabza alma töreni yapılırdı. Bu törenlerin uygulayışında ise çeşitli ritüel ve kaideler bulunurdu (Yücel, 1999). Okmeydanında, Büyük Kabza alma töreninde destar bozan kemankeş ilk olarak meydan şeyhinin ya da vekilinin huzuruna çıkar ve şu ritüel gerçekleşirdi.

Şeyh ; "Ayak yerinde durdum ve $900 \mathrm{gez}$ aşırı ok attım, menzil bozdum diye dava edersin ayak şahitlerin var mı?"

Atıcı ; "Var" diye karşııık vermesi üzerine ayak yeri şahitleri huzura getirilir.

Şeyh, şahitlere hitaben ; "Bu kabza talibi, ayağını ayak yerine düz bastı mı?"

Şahitler ; "Bastı"

Şeyh ; "Destar bozduğunu gördünüz mü?"

Şahitler ; "Gördük"

Şeyh ; "Böyle tanık mısınız?"

Şahitler ; "Tanığız" demesi üzerine meydan şeyhi hava yeri şahitlerini huzuruna ister. Şeyh hava yeri şahitlerine hitaben ; "Talip 900 gez aşırı ok attığını ve destar bozduğunu söyler böyle tanık mısınız?"

Şahitler ; "Tanığız” demesi üzerine;

Talip, meydan şeyhinin önüne gelerek diz çöker. Talibin önüne kabza kısmı üste, çilesi yere gelecek şekilde yay konulur. Talip, sağ eli ile yayın kabzasını tutarak kaldırır ve öper. Daha sonra da ayağa kalkarak meydan şeyhinin elini öper. Şeyh, bunun üzerine "götürün üstadı kabza versin" der ve talip üstadının yanına götürülür (Güven, 2003). 
Metin, S.N. ve Uysal, A. (2020). Osmanlı Devleti Okmeydanlarında Menzil Okçuluğu Eğitimi. Gaziantep Üniversitesi Spor Bilimleri Dergisi, 5(3), 276-285.

Üstadının yanına gelen talip, üstadının elini öper sonra ise üstadın duası için diz çökerdi. Üstat, atııının sol kulağına eğilerek şu duayı ederdi (Yücel, 2015).

"BismillahirRahmani'r Rahim Allahümmesalli ala seyyidina ve beyyina Muhammedin ve ali nur-ı Muhammed Mustafa. Allahümmesalli ala seyyidina Muhammed ve ali Haticetü'l Kubra ve Fatımatu'l Zehra ve İmam Hasanü'l razi ve Imamü'l Hüseyin el mazlumü'l şehid düşen Kerbela ve İmam Zeynelabidin, Muhammed el Bakır ve İmam Cafer el Sadık ve İmam Musa el Kazım ve İmam Muhammedü'l Şafi ve İmam Hasanül Askeri ve İmam Muhammed el Mehdi sahibü'l zaman ve kutbü'l devranü'l kayim el Rıdvan AllahüTeala aleyhim ecmain ve cümle bu tarıkda gelmiş ve geçmiş ehl-i kabza perverleri ihtiyarları ruhu içün ve mevcud olanların ervahı içün ve cümle şehidlerin ve gazilerin ruhu içün ve rical-i gayib içün ve düşmanların kahrı içün fatiharuy-ı pak Resulüllah'a salavat"

Talip duayı dinledikten sonra ayağa kalkar önce üstadının sonra ise orada bulunan bütün kemankeşlerin elini öper ve şeyhin odası ile bitişik olan yan odaya giderdi. Bu odada şeyh talibe kemankeşlik sırını söyler ve Büyük Kabza Alma töreni sona ererdi (Kahraman, 1995:391).

Büyük kabza alan atıcı artık kemankeş ünvanını kullanabilir, padişah huzurunda atış yapabilir ve kolçak takabilirdi.

\section{Okmeydanlarında Menzil Okçuluğu Eğitimi}

Okmeydanlarında menzil okçuluğu eğitimi bir kişinin küçük kabza almasıyla başlar. Atıcı büyük kabza alıp kemankeş ünvanını aldıktan sonra ise okçuluk hayatı boyunca devam eder. Menzil okçuluğu Osmanlı Devleti okçuluk sporu açısından en zor ve en meşakatli olanı sayılabilir.

Küçük kabza alan atıcı menzil okçuluğu için ilk eğitimini kepade ya da kepaze yayı ile başlar. Dilimizde kepaze olmak deyiminin de buradan geldiği düşünülmektedir (Kalafat, 2014; Özden \& Öz, 2015). Çünkü kepade yayı eğitimi uzun süren ve atıcının kas yapısını giderek geliştirerek yüksek kalibreli menzil okçuluğu yaylarına alışması hedeflenirdi. Bu aşamada her spor branşında olduğu gibi menzil okçuluğunda da atıcı hafif bir şekilde antrenman yapar vücudun yavaş yavaş alışması amaçlanırdı (Mustafa Kani Bey, 2010:59).

Kepade eğitimi ilk olarak atııının duruşu ile başlardı. Atıcı kabza tutmayı, ayak duruşları, yay çekmeyi öğrenirdi. Daha sonra ise günde birkaç kez 66 defa olmak üzere yay çekerek kepade idmanı başlardı (Mustafa Kani Bey, 2010:60). Yücel bu 
Metin, S.N. ve Uysal, A. (2020). Osmanlı Devleti Okmeydanlarında Menzil Okçuluğu Eğitimi. Gaziantep Üniversitesi Spor Bilimleri Dergisi, 5(3), 276-285.

sayının günde 500 e kadar çıktığını belirtmiştir (Yücel, 2015:117). İlerleyen günlerde bu sayı arttırılırdı. Kepade yayı atıcının okçuluğa alışmasının ilk idmanı olduğundan ve temel kabul edildiğinden son derece önem verilmiştir. Bazı üstatların kepaze eğitimini ok ile de yaptırırlardı. Bunda amaç ise vücudun sert yay çekimine ok ile birlikte çalışarak çekiş alışkanlığının kazanıımasıdı (Mustafa Kani Bey, 2010:60).

Üstadın olur vermesi ile birlikte atıcı kepade eğitimini tamamlamış olurdu. Kepade eğitimini tamamlayan atıcı bir sonraki eğitim olan hava ya da torba gezi idmanına geçerdi (Yönal \& Türkmen, 2017). Hava gezi idmanı havanın güzel olduğu zamanlar açık alanda, torba gezi idmanı ise havanın kötü olduğu zamanlarda kapalı alanda gerçekleştirildi.

Hava gezi idmanında oklarda temren ve yelek kullanılmaz ve sadece ok ile idman yapılırdı. Burada amaç ise menzil okçuluğu için eğitilen atıcının doğru bir pozisyonda atış yapmasını sağlayabilmekti. Hava gezi idmanlarında günde üç yüz atış yapılması gerekirdi. Bu idmanın ise otuz gün sürmesi önerilmiştir (Mustafa Kani Bey, 2010:65)

Torba gezi idmanında ise oklar temrenli fakat yeleksiz olurdu. Havanın kötü olduğu zamanlar kapalı bir alanda içi talaş dolu hedefe ok atışları yapılırdı. Okun temrenli olmasının sebebi de bu torbaya saplanmasındandır. Ancak bu ok da bulunan temren küçük deri bir topuzdu (Yücel, 2015:118). Bu eğitimde amaç duruşun düzgün yapılarak uzak mesafeye yapılacak olan atışlarda okun salka düşmesini engellemekti. İdmana hafif bir yay ile başlayarak atıcının yapabileceği kadar sertleştirilmeli ve tekrar düşük bir yay ile idman tamamlanmalıydı (Mustafa Kani Bey, 2010:64).

Hava ve torba gezi eğitimleri üstat yeterli buluncaya kadar devam ederdi. Üstat nezaretinde ok meydanında atış yapmaya geçilirdi. Ancak ok meydanında atış yapmak için meydanın elverişli ve müsait olan yerleri belirlenmeliydi. Keza pazartesi ve perşembe günleri menzil sahibi kemankeşler atış yapar ve halkta onları izlemeye geldiğinden kabalık olurdu (Yücel, 2015:118). Haftada iki gün talipler için okmeydanında sınırlı yerler için eğitime izin verilirdi ve bu da Kanunname-i Rumat da belirtilmişti (Kunter, 1942). Okmeydanında menzil atışları için eğitim alan taliplere hemen sert yay verilmesi uygun olmaz öncelikle hafif yaylar ile eğitime başlanır zaman içerisinde yaylar sertleştirilirdi (Yücel, 2015:118).

$\mathrm{Bu}$ eğitimlerin dışında üstat okmeydanında eğitim alan atıcıya geçtiği her aşamada okmeydanı kuralları, kaideleri ve her şeyden önemlisi kemankeş ahlakı 
açısından eğitim vermek ile de sorumluydu. Okmeydanında verilen eğitim ile ilgili olarak Kurthan Fişek, temelinin spor ahlakına dayandığını belirtmiştir (Fişek, 1985:39). Okmeydanlarında verilen bu spor ahlakı eğitimi ve kuralları herkes için geçerliydi. Eşitlik ön planda tutulur atılan menzillerde aynı tip ok ve aynı rüzgarda atış yapması dahi hesaplanırdı. Okçuluk risalelerinde "Burası er meydanıdır. Burada şah'ü geda birdir" sözü de eşitliğin ön planda olduğunun göstergesiydi. Aynı zamanda o dönemin sadrazamı ve kemankeşlerinden olan Sadrazam Kara Mustafa Paşa'nın "Vezirliğim orada kaldı burada içinizden herhangi birisiyim" demesi de bu ahlaki kaidelere duyulan saygının göstergesidir (Yücel, 2015:43).

Atıcının 900 gez aşırı atıp büyük kabza alması ile birlikte okçular sicil defterine ismi yazılır ve kemankeş ünvanını kullanmaya başlardı. Mustafa Kani bir kemankeşin her gün idman yapması gerektiğini eğer yapamıyorsa da en az 66 defa kepade yayı ile çalışması gerektiğini belirtmiştir (Mustafa Kani Bey, 2010). Kemankeş Mustafa ise "sen idmanı bir gün bırakırsan o seni yirmi gün bırakır" diyerek her gün idman yapmanın önemini vurgulamıştır (Kahraman, 1995:392).

\section{Tartışma ve Sonuç}

Türkler tarih boyunca okçu bir millet olarak bilinmiştir. Öyle ki bu Türk milletinin en önemli yazıtı olan Orhun Hitabelerinde dahi kendisini göstermektedir (Baykara, 2001:24). Birçok Türk destanında da ok ve yay kullanılmış ve simgeselleştirilmiştir. Bunların bir tanesi de Oğuz Kağan destanıdır ve hakimiyeti temsil eder (Ögel, 2014:143).

Okçuluk Türkler için tarihi bir miras, bir savaş aleti olmasının yanında daha küçük yaşlardan itibaren çocuklar için bir eğitim faaliyeti, düzenlenen yarışmalar ile de birlik ve beraberlik duygusunu arttırmayı amaçlayan bir spor faaliyetidir (Yıldıran, 1996).

Geçmişten Osmanlı Devleti'ne kadar gelen okçuluk, Osmanlı Devleti'nde ok meydanlarının açılması ve gelişmesiyle 0 dönemin en büyük spor organizasyonlarından biri olmayı başarmıştır. Gerek yönetiminde kemankeşlerin fikirlerinin alınması, gerekse tüm kemankeşlere sağlanan eşit imkanlar düşünüldüğünde fairplay olgusununda geliştiği söylenebilir.

Okmeydanlarının en önemli rekabeti menzil okçuluğuydu. Osmanlı Devleti'nin birçok şehrinde okmeydanı ve bu okmeydanlarında birçok menzil bulunmaktaydı. Ünlü kemankeşler kendilerinden önce atılmış olan menzilleri geçerek, taş dikmek ve 
Metin, S.N. ve Uysal, A. (2020). Osmanlı Devleti Okmeydanlarında Menzil Okçuluğu Eğitimi. Gaziantep Üniversitesi Spor Bilimleri Dergisi, 5(3), 276-285.

isimlerini ölümsüzleştirmek amacındaydı. Bunun için ise hiç bitmeyen bir çalışma gerekliydi.

Kemankeş olup ismini ölümsüzleştirmek isteyen kişi ilk olarak okmeydanına gider ve bu isteğini meydan intiyarlarına belirtirdi. Bu isteği kabul gören kişi ok meydanında eğitim almaya başlardı.

Okmeydanı eğitimlerinin aşamalarına bakıldığında ise; bir atıcının ilk aşama olarak küçük kabza alması gerekliydi. Küçük kabza alan atıcı uzun süren bir kepade yayı eğitiminin yanında ok meydanı kuralları ve kemankeş ahlakı açısından üstadı tarafından eğitilirdi. Yeteri kadar kepade yayı ile çalışan atıcı hava gezi ve torba gezi eğitimlerini alarak bu konuda çok fazla antrenman yapardı. Son olarak okmeydanında atışlar yaparak büyük kabza almasını sağlayacak 900 gez mesafeye atış yapıncaya kadar çalışmalarına devam ederdi.

İkinci aşamada 900 gez atmaya hazır olan atıcı şahitleri ile birlikte meydana gelir ve atışını yapardı. Atıcının attığı ok 900 gez mesafeyi geçerse büyük kabza almaya hak kazanırdı. Büyük kabza almak, okmeydanlarında çeşitli kural ve ritüellerin uygulandığı bir törendi. Büyük kabza alan kişi artık bir kemankeş olup menzil atıp taş dikmeye hak kazanır ve ismini ölümsüzleştirme şansını yakalardı.

Okmeydanlarında menzil okçuluğu eğitiminin çok sistematik ve disiplinli olarak yapıldığı görülmektedir. Sportif bir eğitim olarak düşünüldüğünde, fiziki eğitimin menzil okçuluğunda başarıyı getirebileceği ancak ahlaki eğitimin ise kemankeşliğin temelini oluşturduğu söylenebilir. Okmeydanında alınan eğitimin kemankeşliğin temel eğitimi olması ve devam ettirilmesi önemliydi. Çünkü bir kemankeşin başarısı attığı menzil ile ölçülür, menzil atan kemankeş ise okçuluk risalelerinde ahlaki olarak da tanıtılırdı.

Ahlaki eğitimlerde yardımseverlik, vatanseverlik ve dürüstlüğe özellikle dikkat edilirdi. Bir kemankeş rekor mesafeye atıp taşını dikemeden vefat ederse arkadaşları tarafından taşı dikilir ve ismi ölümsüzleştirilirdi. Bunun dışında bir kemankeş dürüst olmayan bir şekilde gayri ahlaki yollar ve hile ile taş dikmek istediği anlaşılırsa "bizimle oturma" denilerek okmeydanından çıkarılırdı. Birçok kemankeşin savaşlarda şehit ya da gazi olduğu, bazılarının yeniçeri zümresinden olması da dikkate değerdir. Tüm bunlar düşünüldüğünde okmeydanında verilen eğitimin şahsiyet eğitimi açısından da önem arz ettiği görülmektedir.

Okçular sicil defterine ismi yazılan binlerce kemankeş bulunmaktadır ancak menzil atıp ismini ölümsüzleştiren kemankeş sayısı ise çok daha azdır. Bir 
Metin, S.N. ve Uysal, A. (2020). Osmanlı Devleti Okmeydanlarında Menzil Okçuluğu Eğitimi. Gaziantep Üniversitesi Spor Bilimleri Dergisi, 5(3), 276-285.

kemankeşin en büyük arzusunun ismini ölümsüzleştirmek olduğu düşünüldüğünde, çalışmanın ve alınan eğitimlerde ki devamlılığın sağlanmasının bu arzuya ulaşmanın temelini oluşturduğu düşünülebilir.

\section{Kaynaklar}

Acar, Ş., \& Özveri, M. (2017). Bir İstanbul Okçuluk Menzilnâmesi. Osmanlı Bilimi Araştırmaları, 18(2), 24-58.

Akın Zorba, H. (2014). Sport in the Ottoman Empire in Evliya Çelebi's Seyahatnâme. International Journal of Science Culture and Sport, 2(5), 721-732. https://doi.org/10.14486/IJSCS142

Aktepe, K. (2012). Okçuluk. İstanbul: Nobel Akademik Yayıncılık.

Archer, C. I., \& Ferris, J. R. (2002). Dünya Savaş Tarihi. İstanbul: Ezgi Matbaacılık.

Atalay, A., \& Akbulut, A. K. (2013). Türk Spor Kültürünün Eşsiz Örneği: Okçular Tekkesi. Karadeniz Uluslararası Bilimsel Dergi, 1(18), 144-154.

Ayanoğlu, İ. F. (1974). Ok Meydanı ve Okçuluk Tarihi. İstanbul: Vakıflar Genel Müdürlüğü Yayınları.

Baykara, T. (2001). Türk Kültür Tarihine Bakışlar. Ankara: Atatürk Kültür Merkezi Yayınları.

Bir, A., Kaçar, M., \& Acar, Ş. (2006). Türk Menzil Okçuluğu, Yay ve Okları. Osmanlı Bilimi Araştırmaları, 8(1), 39-67.

Dever, A., \& İslam, A. (2015). Tarihsel Süreç İçerisinde Türk Kültüründe Spor Algısı. Manas Sosyal Araştırmalar Dergisi, 5.

Fişek, K. (1985). Yüz Soruda Türkiyede Spor Tarihi. İstanbul: Gerçek Yayınevi.

Güven, Ö. (2003). Geleneksel Okçuluk ve Güreş Sporunda Ahiliğin Etkileri. Türk Kültürü ve Hacı Bektaş Veli Araştırma Dergisi, 27, 1-31.

Kahraman, A. (1995). Osmanlı Devleti'nde Spor (Birinci). Ankara: Kültür Bakanlığı Başvuru Eserleri.

Kalafat, Ş. (2014). Alan Dili Söz Varlığının Genel Dildeki İlişkileri Üzerine: Spor Terimleri Örneği. Uludağ Üniversitesi Fen-Edebiyat Fakültesi Sosyal Bilimler Dergisi, 27.

Küçük, M. A. (2018). İslam Öncesinden Sonrasına Türk Geleneğinde Bir Yaşam Stili:"Okçuluk". İnternational Journal of Cultural and Social Studies (IntJCSS), 4(1), 178-191.

Kunter, H. B. (1942). Atıcılar Kanunnamesi. Tarih Vesikaları, 10, 253-274. 
Mustafa Kani Bey. (2010). Telhis-i Resailat-ı Rumat.(Çev:Yavuz,K., Canatar,M.) Ed:Yüksel,İ.A., İstanbul: İstanbul Fetih Cemiyeti.

Ögel, B. (2014). Türk Mitolojisi I. Cilt (6th ed.). Ankara: Türk Tarih Kurumu Yayınları. Özden, H., \& Öz, S. (2015). Türk Okçuluk Tarihi. İstanbul: Uluslararası Kalkınma ve İşbirliği Derneği.

Vural, H., \& Aksoy, Y. M. (2010). Kavsname Kemankeş Mustafa Efendi. Tokat: Taşhan Yayınları.

Yıldıran, İ. (1996). Uygulama Nedenleri ve Fonksiyonları Bakımından Türk Kültürünün Erken Devirlerinde Bazı Sportif Aktivitelerin Görünümü. Gazi Beden Eğitimi ve Spor Bilimleri Dergisi, 1(2), 47-57.

Yönal, G., \& Türkmen, M. (2017). Türk Kültür Yaşamında Okçuluk. Akademik Sosyal Araştırmalar Dergisi, 55, 523-533.

Yücel, Ü. (1999). Türk Okçuluğu. Ankara: Atatürk Kültür Merkezi Yayınları. 